$\left(\begin{array}{ccc}\text { Jpn. } & \text { J. Hosp. } & \text { Pharm. } \\ 23(3) & 225-230 & (1997)\end{array}\right)$

\title{
保存剤を含有していない0.125\%チロキサポール吸入液に おける一回量包装の有用性
}

杉山一覚*，高橋淳一，井手上寿美佳，金子幸恵，松本富夫，建部 守 獨協医科大学越谷病院薬郕部

\section{Usefulness of One Dose Packages of 0.125\% Tyloxapol Solutions for Inhalation without Preservatives}

\author{
IKKAKU SUGIYAMA*, JUNICHI TAKAHASHI, SUMIKA IDEGAMI, SACHIE KANEKO, \\ TOMIO MATSUMOTO and MAMORU TATEBE \\ Department of Pharmacy, Koshigaya Hospital, \\ Dokkyo University School of Medicine†
}

$$
\left(\begin{array}{l}
\text { Received December 12, } 1996 \\
\text { Accepted February 18, } 1997
\end{array}\right)
$$

By comparing the usual method of measuring medication dosage in medical cups in our hospital (A packages) with newly developed one dose packages (B, C packages) the stability of the ingredients, the sterility of the material, and the accuracy of the correctness of the measuring the samples, we assessed the usefulness of one dose packages of preservativefree $0.125 \%$ tyloxapol solutions for the administration of oral medications. The results were as follows : 1) $\mathrm{pH}$ tended to rise in $\mathrm{A}$ as the strage temperature increased but was stable in both $B$ and $C$. No changes in the external appearance were detectable in any of them. 2) No microbial contamination was found in any of the packages, A, B or C. 3) The measuring accuracy was better in $\mathrm{B}$ and $\mathrm{C}$ than in $\mathrm{A}$. Thus, the one dose packages appeared to be more useful than the usual method of measuring drugs using medical cups as a method by which $0.125 \%$ tyloxapol solutions for inhalations can be used safely and conveniently even when supplied to patients.

Key words — drug packaging, drug contamination, pharmaceutical preservatives, inhalation administration, nebulizers and vaporizers, tyloxapol

保存片を含有していない $0.125 \%$ チロキサポー ル吸入液は成分そのものは経時的に安定である が ${ }^{1)}$ ，現在行われている吸入液の供給方法では，

†越谷市南越谷2-1-50;2-1-50, Minami-kosigaya, Kosigaya-shi 343 Japan
調製せずに瓶のまま交付する方法にしても，薬剤 師が医師からの処方篦により必要量を調製して交 付する方法にしても，微生物污染を防ぐことはで きず2-4), 計量困難についても改善される見込み はない5). 
そこで, 著者らは成分の安定性, 試料の無菌 性, 試料分取の正確性の観点から，0.125\%チロ キサポール吸入液が患者のもとに供給後も安全か つ簡便に使用される方法として，市販製品に改良 を施した一回量包装を試作し，当院における従来 の薬杯による計量方法と比較することによ り， $0.125 \%$ チロキサポール吸入液の一回量包装 の有用性についての検討を行ったので, ここに報 告する.

\section{実 験 の 部}

\section{1. 試料}

今回の調査には，試料として $0.125 \%$ チロキサ ポール吸入液 (日本商事, 大阪, 以下 $\mathrm{TP}$ ) を用 いた。

\section{2. 包装および試料の充填}

今回の実験に用いた包装は $100 \mathrm{ml}$ の滅菌済みの 褐色ポリエチレン製容器 A (馬野化学容器, 大 阪),ポリエチレンテレフタレート/アルミニウム/ ポリエチレンテレフタレート/ポリエチレンの四 層構造からなる銀色の包装フィルム（凸版印刷, 東京)を折り重ねて,出来上がり外寸法をそれぞれ 一辺 $5.6 \mathrm{~cm}, 6.0 \mathrm{~cm}, 7.0 \mathrm{~cm}$ の3種類の正三角形, 4.0 $\mathrm{cm} \times 2.8 \mathrm{~cm}, 5.0 \mathrm{~cm} \times 3.5 \mathrm{~cm}, 5.5 \mathrm{~cm} \times 4.25 \mathrm{~cm}$ の 3 種類の四角形になるように加工した包装 B，C である.なお， B およびCの包装は試料の充填 に必要な一辺を残して, マイクロシーラー（日科 ミクロン, 東京) を用いて接着後, エチレンオキ サイドによる滅菌処理を施した。 その後, 無菌的 に試料を A に $25 \mathrm{ml}, 50 \mathrm{ml}, 100 \mathrm{ml}$ ずつ充填した ものを $\mathrm{A}_{0.5}, \mathrm{~A}_{1.0}, \mathrm{~A}_{2.0}, \mathrm{~B} に 0.5 \mathrm{ml}, 1.0 \mathrm{ml}, 2.0$ $\mathrm{ml}$ ずつ充填したものを $\mathrm{B}_{0.5}, \mathrm{~B}_{1.0}, \mathrm{~B}_{2.0}, \mathrm{C} に 0.5$ $\mathrm{ml}, 1.0 \mathrm{ml}, 2.0 \mathrm{ml}$ ずつ充填したものを $\mathrm{C}_{0.5}, \mathrm{C}_{1.0}$, $\mathrm{C}_{2.0}$ とした. また, $\mathrm{B}_{0.5}, \mathrm{~B}_{1.0}, \mathrm{~B}_{2.0}$ および $\mathrm{C}_{0.5}, \mathrm{C}_{1.0}$, $\mathrm{C}_{2.0}$ に試料を充填する操作はジャスター1100DG, DG1000および5000（ニチリョウ，東京）を用い て正確に行い, その後, 未接着の一辺をマイクロ シーラーにて接着した。

\section{3. 外観観察および pH 測定}

$\mathrm{A}\left(\mathrm{A}_{0.5}, \mathrm{~A}_{1.0}, \mathrm{~A}_{2.0}\right), \mathrm{B}\left(\mathrm{B}_{0.5}, \mathrm{~B}_{1.0}, \mathrm{~B}_{2.0}\right), \mathrm{C}\left(\mathrm{C}_{0.5}\right.$, $\left.\mathrm{C}_{1.0}, \mathrm{C}_{2.0}\right)$ を $4{ }^{\circ} \mathrm{C}, 25^{\circ} \mathrm{C}, 35^{\circ} \mathrm{C}$ 温度条件下で遮 光保存し, 充填された試料の色調の変化, 混濁の 有無について，10週間; 肉眼で観察した後, $\mathrm{pH}$ 測定を行った。なお, $\mathrm{pH}$ 測定には日立堀場 $\mathrm{pH}$ メーターF-8型（堀場製作所, 京都）を用いた。 また, 測定は 2 回行い, その平均值を $\mathrm{pH}$ 值と し, $\mathrm{B}_{0.5}, \mathrm{C}_{0.5}$ は各々 2 包装分を合わせ, 計 $1 \mathrm{ml}$ としたものを測定した。

\section{4. 充填された試料中の生菌数の測定}

$\mathrm{A}\left(\mathrm{A}_{0.5}, \mathrm{~A}_{1.0}, \mathrm{~A}_{2.0}\right), \mathrm{B}\left(\mathrm{B}_{0.5}, \mathrm{~B}_{1.0}, \mathrm{~B}_{2.0}\right), \mathrm{C}\left(\mathrm{C}_{0.5}\right.$, $\left.\mathrm{C}_{1.0}, \mathrm{C}_{2.0}\right)$ を $4{ }^{\circ} \mathrm{C}, 25^{\circ} \mathrm{C}, 35^{\circ} \mathrm{C}$ の温度条件下で遮 光保存し, 1 週間ごとに 10 週間, 各包装 2 サンプ ルずつ，寒天平板表面塗沫法により，充填された 試料 $1 \mathrm{ml}$ あたりの生菌数を測定した。なお，培 地は一般細菌用として SCD 寒天培地(栄研化 学, 東京), 真菌用として GP 寒天培地 (日本製 薬，東京）を用いた。また, 培養温度および時間 は一般細菌用 $35^{\circ} \mathrm{C}, 72$ 時間, 真菌用 $25^{\circ} \mathrm{C}, 120$ 時 間とした。

\section{5. 分取重量の測定と容量への变換}

$\mathrm{A}_{0.5}$ は $0.5 \mathrm{ml}, \mathrm{A}_{1.0}$ は $1.0 \mathrm{ml}, \mathrm{A}_{2.0}$ は $2.0 \mathrm{ml}$ ずつ, 薬杯を用いて試料を取り出す操作（以下, 分取) を各30回を行い，試料を充填した各包装の分取操 作前後の重量を測定し，TPの比重 $\left(\mathrm{d}^{20} 1.025\right)$ を用い, 式(1)により各容量（以下, 分取容量) に変換した. $\mathbf{B}_{i}\left(\mathbf{B}_{0.5}, \mathbf{B}_{1.0}, \mathbf{B}_{2.0}\right), \mathrm{C}\left(\mathrm{C}_{0.5}, \mathrm{C}_{1.0}\right.$, $\mathrm{C}_{2.0}$ ）は試料を充填した各包装の分取操作前後の 重量を30回測定し, 式(1)により各分取容量に変 換した。ただ， B，Cの包装からの試料の分取 に際しては, 人間の手指の力で可能な範囲で充填 された試料を絞り出すように行い, 特別な器具, 装置は用いなかった。

$$
\begin{aligned}
& \mathrm{V}_{\mathrm{A}}, \mathrm{V}_{\mathrm{B}}, \mathrm{V}_{\mathrm{C}}=\left(\mathrm{W}_{1}-\mathrm{W}_{2}\right) / 1.025 \cdots \cdots(1) \\
& \mathrm{V}_{\mathrm{A}}, \mathrm{V}_{\mathrm{B}}, \mathrm{V}_{\mathrm{C}} \text { : 分取容量 } \mathrm{A}, \mathrm{B}, \mathrm{C}(\mathrm{ml}) \\
& \mathrm{W}_{1} \text { : 分取操作前重量 }(\mathrm{g}) \\
& \mathrm{W}_{2} \text { : 分取操作後重量 }(\mathrm{g})
\end{aligned}
$$

なお, $\mathrm{A}$ の容器からの分取に際しては, 片側が 最小目盛り $0.5 \mathrm{ml}$ で最大 $2 \mathrm{ml}$ まで計量可能なポ 
リスチレン樹脂製の薬杯（今回は未使用の残りの 片側は最小目盛り $1 \mathrm{ml}$ で最大 $10 \mathrm{ml}$ まで計量可 能）を用いた。また，重量はメトラー分析用上血 電子天秤 AE160型（日本シイベルヘグナー，神 奈川）を用いて測定した。

\section{6. 分取容量データの正規分布性の確認}

各包装に充填された試料の30回分の分取容量デ 一タの正規分布性の確認を歪度，尖度および $\chi^{2}$ 適合度検定により行った。

なお, $\mathrm{p}<0.05$ 統計学的有意とした.

\section{結果}

\section{1. 外観変化および pH 変化}

各包装に充填された試料の外観観察では, 経時 的外観変化はいずれも10週間認められなかった.
また, pH 測定結果は Table 1 に示す。

\section{2. 充填された試料の無菌性}

各包装に充填された試料の無菌性を調査したと ころ, いずれの条件においても生菌は10週間認め られなかった。

\section{3. 分取容量データの統計学的特性值}

各包装に充填された試料の30回分の分取容量デ 一タの統計学的特性值を Table 2 に示す.

4. 分取容量データの正規分布性の判定

各分取容量データの歪度から, $\mathrm{A}_{1.0}, \mathrm{~B}_{2.0}$, $\mathrm{C}_{0.5}, \mathrm{C}_{1.0}$ は右裾広がり，その他の包装タイプは左 裾広がりの分布であることがわかった。また，尖 度から， $\mathrm{C}_{1.0}$ は正規分布に比し，尖った分布であ り，その他の包装タイプは扁平であることがわか った（Table 2).

Table 1. Change of $\mathrm{pH}$ during Storage

\begin{tabular}{|c|c|c|c|c|c|c|c|}
\hline \multirow{2}{*}{$\begin{array}{l}\text { Storage } \\
\text { condition }\end{array}$} & \multirow{2}{*}{\multicolumn{2}{|c|}{ Package type }} & \multirow{2}{*}{ Initial } & \multicolumn{4}{|c|}{ Weeks } \\
\hline & & & & 1 & 3 & 5 & 10 \\
\hline \multirow{7}{*}{$\begin{array}{c}\quad 4{ }^{\circ} \mathrm{C} \\
\text { Prevention } \\
\text { of light }\end{array}$} & \multirow[t]{7}{*}{$\mathbf{A}_{0.5}, \mathbf{A}_{1.0}$} & $\mathrm{~A}_{2.0}$ & 8.3 & 8.4 & 8.4 & 8.5 & 8.6 \\
\hline & & $\mathbf{B}_{0.5}$ & 8.3 & 8.5 & 8.5 & 8.5 & 8.5 \\
\hline & & $\mathrm{B}_{1.0}$ & 8.3 & 8.4 & 8.4 & 8.4 & 8.4 \\
\hline & & $\mathbf{B}_{2.0}$ & 8.3 & 8.4 & 8.3 & 8.3 & 8.4 \\
\hline & & $\mathrm{C}_{0.5}$ & 8.3 & 8.5 & 8.4 & 8.4 & 8.4 \\
\hline & & $\mathrm{C}_{1.0}$ & 8.3 & 8.5 & 8.5 & 8.3 & 8.4 \\
\hline & & $\mathrm{C}_{2.0}$ & 8.3 & 8.3 & 8.3 & 8.3 & 8.3 \\
\hline $25^{\circ} \mathrm{C}$ & \multirow[t]{7}{*}{$\mathrm{A}_{0.5}, \quad \mathbf{A}_{1.0}$} & $\mathrm{~A}_{2.0}$ & 8.3 & 8.4 & 8.7 & 8.7 & 8.9 \\
\hline \multirow{6}{*}{$\begin{array}{c}\text { Prevention } \\
\text { of light }\end{array}$} & & $\mathrm{B}_{0.5}$ & 8.3 & 8.5 & 8.6 & 8.5 & 8.5 \\
\hline & & $\mathrm{B}_{1.0}$ & 8.3 & 8.4 & 8.4 & 8.4 & 8.3 \\
\hline & & $\mathrm{B}_{2.0}$ & 8.3 & 8.3 & 8.3 & 8.3 & 8.3 \\
\hline & & $\mathrm{C}_{0.5}$ & 8.3 & 8.4 & 8.3 & 8.3 & 8.4 \\
\hline & & $\mathrm{C}_{1.0}$ & 8.3 & 8.4 & 8.5 & 8.4 & 8.4 \\
\hline & & $\mathrm{C}_{2.0}$ & 8.3 & 8.3 & 8.3 & 8.3 & 8.3 \\
\hline $35^{\circ} \mathrm{C}$ & \multirow[t]{7}{*}{$\mathrm{A}_{0.5}, \mathrm{~A}_{1.0}$} & $\mathrm{~A}_{2.0}$ & 8.4 & 8.4 & 8.8 & 8.8 & 9.0 \\
\hline Prevention & & $\mathbf{B}_{0.5}$ & 8.4 & 8.5 & 8.5 & 8.6 & 8.5 \\
\hline \multirow[t]{5}{*}{ of light } & & $B_{1.0}$ & 8.4 & 8.4 & 8.5 & 8.5 & $8 . \dot{5}$ \\
\hline & & $\mathrm{B}_{2.0}$ & 8.4 & 8.3 & 8.3 & 8.3 & 8.3 \\
\hline & & $\mathrm{C}_{0.5}$ & 8.4 & 8.4 & 8.4 & 8.4 & 8.4 \\
\hline & & $\mathrm{C}_{1.0}$ & 8.4 & 8.4 & 8.5 & 8.3 & 8.5 \\
\hline & & $\mathrm{C}_{2.0}$ & 8.4 & 8.3 & 8.4 & 8.3 & 8.3 \\
\hline
\end{tabular}

Each value represents the mean of two samples. 
Table 2. Statistical Characteristics of Distribution of the Actual Volumes of the Samples according to Package Type

\begin{tabular}{ccccccccccr}
\hline $\begin{array}{c}\text { Package } \\
\text { type }\end{array}$ & No. & $\begin{array}{c}\text { Mean } \\
(\mathrm{ml})\end{array}$ & $\begin{array}{c}\text { SD } \\
(\mathrm{ml})\end{array}$ & $\begin{array}{c}\text { Median } \\
(\mathrm{ml})\end{array}$ & $\begin{array}{c}\mathrm{Q} \\
(\mathrm{ml})\end{array}$ & $\begin{array}{c}\text { Min } \\
(\mathrm{ml})\end{array}$ & $\begin{array}{c}\text { Max } \\
(\mathrm{ml})\end{array}$ & $\begin{array}{c}\text { Range } \\
(\mathrm{ml})\end{array}$ & Skewness & Kurtosis \\
\hline $\mathrm{A}_{0.5}$ & 30 & 0.567 & 0.050 & 0.575 & 0.038 & 0.448 & 0.654 & 0.206 & -0.543 & -0.376 \\
$\mathrm{~A}_{1.0}$ & 30 & 1.125 & 0.088 & 1.119 & 0.039 & 0.978 & 1.401 & 0.423 & 1.016 & 2.007 \\
$\mathrm{~A}_{2.0}$ & 30 & 2.021 & 0.061 & 2.029 & 0.038 & 1.890 & 2.144 & 0.254 & -0.427 & -0.078 \\
$\mathrm{~B}_{0.5}$ & 30 & 0.492 & 0.004 & 0.493 & 0.003 & 0.480 & 0.499 & 0.019 & -1.000 & 1.402 \\
$\mathrm{~B}_{1.0}$ & 30 & 0.976 & 0.013 & 0.976 & 0.009 & 0.946 & 0.997 & 0.051 & -0.404 & -0.201 \\
$\mathrm{~B}_{2.0}$ & 30 & 1.962 & 0.020 & 1.962 & 0.020 & 1.933 & 2.000 & 0.067 & 0.099 & -1.127 \\
$\mathrm{C}_{0.5}$ & 30 & 0.494 & 0.006 & 0.493 & 0.003 & 0.485 & 0.513 & 0.028 & 1.186 & 1.944 \\
$\mathrm{C}_{1.0}$ & 30 & 0.984 & 0.011 & 0.984 & 0.006 & 0.963 & 1.024 & 0.061 & 1.476 & 5.223 \\
$\mathrm{C}_{2.0}$ & 30 & 1.950 & 0.016 & 1.951 & 0.012 & 1.908 & 1.975 & 0.067 & -0.503 & -0.088 \\
\hline
\end{tabular}

No. : Number of samples, SD : Standard deviation, Q : Quartile deviation

さらに $\chi^{2}$ 適合度検定により，各分取容量はいず れも非正規分布であることがわかった Table 3 ).

Table 3. Chi-square Test for Goodness of Fit of the Actual Volumes of the Samples according to Package Type

\begin{tabular}{crc}
\hline $\begin{array}{c}\text { Package } \\
\text { type }\end{array}$ & $\chi^{2}$ & \multicolumn{1}{c}{$\begin{array}{c}\mathrm{P} \\
\text { Value }\end{array}$} \\
\hline $\mathrm{A}_{0.5}$ & 5.34 & $<0.025$ \\
$\mathrm{~A}_{1.0}$ & 16.32 & $<0.001$ \\
$\mathrm{~A}_{2.0}$ & 3.91 & $<0.05$ \\
$\mathrm{~B}_{0.5}$ & 14.54 & $<0.001$ \\
$\mathrm{~B}_{1.0}$ & 6.46 & $<0.02$ \\
$\mathrm{~B}_{2.0}$ & 10.55 & $<0.002$ \\
$\mathrm{C}_{0.5}$ & 18.43 & $<0.001$ \\
$\mathrm{C}_{1.0}$ & 26.46 & $<0.001$ \\
$\mathrm{C}_{2.0}$ & 7.86 & $<0.01$ \\
\hline
\end{tabular}

Each sample was $30, \mathrm{k}=4, \mathrm{df}=1$

\section{考察}

先に，著者らは調製吸入液が微生物污染を受け ずに安全に患者に使用されるためには，保存剤の 添加が必要不可欠であることを報告した ${ }^{3,4)}$.

しかしながら，一方では，吸入液中に添加され
た保存䩹が喘息を惹起したとの報告もあることか $5^{6-11)}$, 可能であるならば吸入液中への保存剤の添 加は回避することが望ましい。

また，現在行われている吸入液の供給方法で は，調製せずに瓶のまま交付する方法にしても， 薬剤師が医師からの処方嘎により必要量を調製し て交付する方法にしても，計量の際に困難を伴 い，液をこぼしてしまう可能性もある ${ }^{5)}$.

そこで，試料の絞り出し操作の繁雑さ，包装材 料の浪費等の欠点も考えられるが, 安定性, 無菌 性，分取の正確性の点から，薬杯による計量方法 と市販製品の改良案として試作した一回量包装を 比較することにより，TPの一回量包装の有用性 について検討した。

包装は現在，当院で使用している褐色ポリエチ レン製容器と新たに一回量包装用に四層構造から なる銀色の包装フィルムを選定した。なお，後者 は分取操作性，分取正確性，携帯性を考虑し，正 三角形および四角形とし，さらに，試料を充填し た際に空白がなるべく残らない包装サイズとし た.

A からの試料分取に際しては，薬液に直接接触 することになるスポイトあるいはディスポーザブ ルシリンジは，それ自体が微生物污染を受け易 い4.12) との報告があるので，本研究においてはそ 
れらの器具を使用せず, 最小目盛りが $0.5 \mathrm{ml} て ゙$ 最 大 $2 \mathrm{ml}$ まで計量可能な薬杯を用いた.

B，Cの各包装にはデジタルマイクロピペット を用いて正確に薬液を充填した。

\section{1. 充填された試料の安定性}

経時的外観変化はいずれも10週間認められなか ったが, 経時的 $\mathrm{pH}$ 変化については $\mathrm{A} の \mathrm{pH}$ は上 昇傾向にあり, なおかつ, 保存温度が高いほど

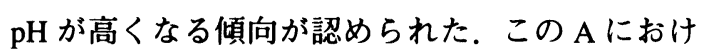
る $\mathrm{pH}$ の上昇は $\mathrm{TP}$ 中に含有される炭酸水素ナト リウムの分解により ${ }^{13)}$, 炭酸ガスが発生し, 酸・ 塩基平衡が崩れ，それを補う方向に反応が進んだ ためと考える.すなわち, $2 \mathrm{NaHCO}_{3} \rightarrow \mathrm{Na}_{2} \mathrm{CO}_{3}$ $+\mathrm{CO}_{2}+\mathrm{H}_{2} \mathrm{O}$ なる化学反応が経時的に促進した ため $\mathrm{pH}$ の上昇が見られたと考える。しかし，B， $\mathrm{C}$ はいずれの温度でも安定した結果が得られた。

なお, TPの経時的な成分の安定性はすでに確 認されているが1)，今回の実験における $\mathrm{A} の \mathrm{pH}$ の上昇傾向から判断すると, Aより $\mathrm{B}, \mathrm{C}$ のほう がより成分の安定性を確保できると考える.

\section{2. 充填された試料の無菌性}

各包装に充填された試料の無菌性を調査したと ころ, いずれの条件においても生菌は認められな かった。従って，いずれの包装も開封されるまで は, 気密性が保持され得ることが確認された。し かしながら，使用のたびごとにキャップの開栓を 余儀なくされる A はそのたびごとに微生物污染

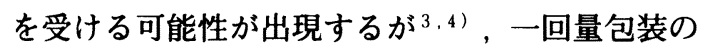
B,C は包装の気密性が保持され得るなら，その可 能性はないものと考える.

従って, 微生物污染を受ける可能性がないとい う点から判断すると, Aより $\mathrm{B}, \mathrm{C}$ が包装として 優れていると考える.

\section{3. 分取容量データの正規分布性}

各30回分の分取容量データの分布を確認したと ころ, 歪度から, 各分布は左右対称ではなく, 中 心から見ていずれかの側に多くの測定值が偏って おり,また, 尖度から, 各分布は正規分布に比 し, 測定值が集中しているか, あるいはその逆に
集中の程度が低いことがわかった（Table 2).

また, 各分布が理論度数分布とどの程度合致し ているかを $\chi^{2}$ 適合度検定により調べたところ,各 $\chi^{2}$ 值より, 各分取容量データの分布はいずれも 正規分布から偏った分布, すなわち, 非正規分布 であることがわかった（Table 3 ).

従って, 各30回分の分取容量データの分布はい ずれも非正規分布であると判断した.

\section{4. 試料分取の正確性の比較}

充填された試料の分取の正確性の比較を Table 2 に示した統計学的特性值を用いて, 理論分取容 量 $\left(\mathrm{A}_{0.5}, \mathrm{~B}_{0.5}, \mathrm{C}_{0.5}\right.$ の場合は $0.500 \mathrm{ml}, \mathrm{A}_{1.0}, \mathrm{~B}_{1.0}$, $\mathrm{C}_{1.0}$ は $1.000 \mathrm{ml}, \mathrm{A}_{2.0}, \mathrm{~B}_{2.0}, \mathrm{C}_{2.0}$ は $\left.2.000 \mathrm{ml}\right)$ グル ープごとに行った. 但し, 前述のように, 本研究 データの分布がいずれも非正規分布であることか ら，代表值として中央值，散布度として範囲およ び四分位偏差を用いた。

まず，各分取容量の中央値を比較すると，いず れの容量においても，A は B，Cに比べ，大きな 值を示した（Table 2).

次に, 各分取容量の範囲および四分位偏差を比 較したところ, どちらの特性値も A は B , C の 各值より大きな值を示した。すなわち，A は B, Cに比べ, いずれの容量においてもデータの散布 度，すなわち，バラッキが大きいことが確認され た (Table 2).

従って, 試料を正確に分取するという点から判 断すると， A より B， C が包装として優れている と考える.

以上の結果から, 保存剤を含有していない TP が患者のもとに供給後も安全かつ簡便に使用され る方法として, 従来の薬杯による計量方法に比 し，一回量包装は有用であると考える.

謝辞 本研究の遂行にあたり，協力いただいた獨 協医科大学越谷病院薬棛部の戸張敬子, 内藤由美, 萩 原洋子, 岸田典子, 各氏に感謝する。

\section{引用文献}

1) 杉山一党, 浅見博子, 鈴木幸恵, 西岡洋子, 戸 
張敬子, 内藤由美, 松本富夫, 建部守, JJSHP, 30, 1161-1166 (1994).

2) 尾家重治, 神谷晃, 防菌防徽, 21, 233-236 (1993).

3）杉山一覚, 浅見博子, 鈴木幸恵, 高田洋子, 戸 張敬子, 松本富夫, 建部守, 小堀一乃, 森三樹 雄, 病院薬学, 20, 219-224 (1994).

4) 杉山一覚, 柿㟝正子, 浅見博子, 戸張敬子, 内 藤由美, 松本富夫, 建部守, 小堀一乃, 森三樹 雄, 病院薬学, 20, 392-398 (1994):

5）杉山一覚, 杮㟝正子, 浅見博子, 高田洋子, 戸 張敬子, 松本富夫, 建部守, 病院薬学, 19, 450 -457 (1993).

6) D. H. Bryant and P. Rogers, Chest, 102, 742-747 (1992).

7) R. L. Henry, R. G. Hankin and R. Abramson, Aust. Paediatr. J., 25, 86-88 (1989).
8) Q. Summers and R. Tarala, Lancet, 2, 740741 (1989).

9) W. Wright, Y. G. Zhang, C. M. Salome and A. J. Woolcock, Am. Rev. Respir. Dis., 141, 1400-1404 (1990).

10) Y. G. Zhang, W. J. Wright, W. K. Tam, T. H. Nguyen-Dang, C. M. Salome, and A. J. Woo lcock, Am. Rev. Respir. Dis., 142, 1405-1408 (1990).

11) C.K.W. Lai, C.H.S. Chan, Thorax, 48, 566568 (1993).

12) M. Castle, J. H. Tenney, M. P. Weinstein, and T. C. Eichhoff, Heart Lung, 7, 641-644 (1974).

13) 西垣貞夫, 南武夫, 雪下君子, 深尾裕美, 沢地 次男, JJSHP, 20, 37-43 (1984). 